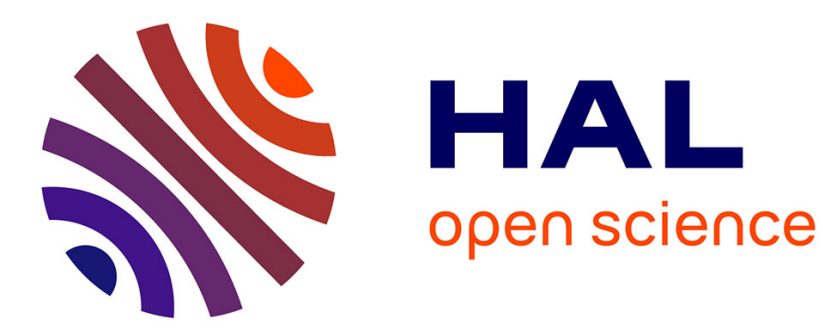

\title{
Collinear mirage effect at a microscopic scale
}

L. Pottier, A. Boccara

\section{To cite this version:}

L. Pottier, A. Boccara. Collinear mirage effect at a microscopic scale. Journal de Physique IV Proceedings, 1994, 04 (C7), pp.C7-75-C7-77. 10.1051/jp4:1994719 . jpa-00253247

\section{HAL Id: jpa-00253247 https://hal.science/jpa-00253247}

Submitted on 1 Jan 1994

HAL is a multi-disciplinary open access archive for the deposit and dissemination of scientific research documents, whether they are published or not. The documents may come from teaching and research institutions in France or abroad, or from public or private research centers.
L'archive ouverte pluridisciplinaire HAL, est destinée au dépôt et à la diffusion de documents scientifiques de niveau recherche, publiés ou non, émanant des établissements d'enseignement et de recherche français ou étrangers, des laboratoires publics ou privés. 


\title{
Collinear mirage effect at a microscopic scale
}

\author{
L. Pottier and A.C. Boccara
}

Laboratoire d'Optique de l'E.S.P.C.I., Centre National de la Recherche Scientifique et Université Pierre et Marie Curie, 10 rue Vauquelin, 75005 Paris, France

\begin{abstract}
This demonstration of mirage effect under a microscope provides a new possibility to measure the thermal diffusivity of a transparent sample as small as a few microns, with micronic spatial resolution.
\end{abstract}

Mirage effect [1] is now a classical technique of photothermal physics. The modulated heating beam is focused at normal incidence on the sample's surface, while the probe beam runs either along the surface (transverse configuration) or along the heating beam (collinear configuration, for transparent samples; $\mathrm{cf}$. figure 1). The probe beam senses the modulated temperature gradient all along its path in the heated region, and is deviated accordingly. The characteristic lengths (beam waist diameters; thermal diffusion length in the sample) are usually of the order of one tenth of a millimetre. Mirage effect has been extensively used to study the transport of heat, of carriers, of mass, etc...[2-4].

The present work presents a demonstration of mirage effect under a microscope, with characteristic lengths one order of magnitude smaller (beam diameter $\approx 8 \mu \mathrm{m}$; thermal diffusion length in the sample $\approx 17 \mu \mathrm{m}$ ). The interest is precisely this reduction of the exploration scale. A stronger reduction could be achieved, in view of the good signal/noise ratio obtained here.

The experiment was performed with a set-up actually designed for photoreflectance microscopy. The heating beam $\left(\mathrm{Ar}^{+}, 514 \mathrm{~nm}\right)$ and the probe beam (diode laser, $670 \mathrm{~nm}$ ) both enter the microscope through the eyepiece downwards and are focused in the sample under the objective. A dichroic mirror that reflects the heating beam but transmits the probe beam, makes it possible to scan the heating spot while the probe spot remains fixed.

The sample, a plate of amorphous silica, is transparent for both beams - yet its slight absorption is sufficient for the green beam to heat it to a measurable amount. The two beams transmitted by the sample (fig. 1) reach a filter that blocks the heating beam but transmits the probe beam. This filter is located far from the focal plane of the beams, so as to minimise the energy density and the ensuing mirage signal that would else be induced in the bulk of the filter. The probe beam finally reaches a position sensor, composed of 2 adjacent sectors of a 4-quadrant photodiode. The 2 output voltages are fed into the differential inputs of a lock-in 
amplifier. The position sensor is adjusted for the signal to vanish when the heating spot and the probe spot coincide.

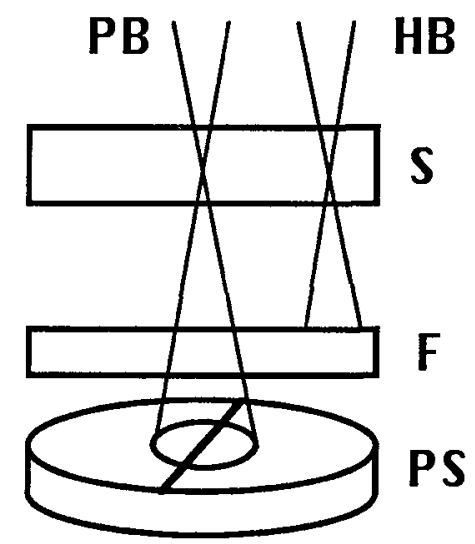

Figure 1 : Principle of the set-up. PB: probe beam; HB: heating beam; S: sample; F: filter; PS: position sensor. The beams are focused on the sample by a commercial microscope (not represented).

The heating spot is swept along a straight line orthogonal to the common boundary of the two sectors of the sensor. This line passes through the centre of the probe spot, located on the boundary. Figure 2 shows the phase lag of the deviation of the probe beam as a function of the position of the heating spot.

The essential features of the plot of figure 2 are easy to understand :

First, since the centre of the probe spot is a symmetry centre for the experiment, the deviations of the probe beam at two symmetric locations $x$ and $-x$ are opposite. Consequently we expect the corresponding phases to differ by $180^{\circ}$, i.e. to satisfy the relation

$$
\Phi(-x)=\Phi(x) \pm 180^{\circ} \text {. }
$$

The two branches of the plot should thus be symmetrical with respect to the ordinate axis with an additional vertical shift of $180^{\circ}$. This is essentially realised on the plot, except far on the wings, where the modulation depth becomes so small that systematic discrepancies dominate.

Next, when both spots coincide $(x=0)$, the heat deposited by the heating beam has no distance at all to travel before it causes the probe beam to deviate. Consequently, we expect zero phase lag between the heating beam's modulation and the probe beam's deviation. The phase lag observed at $x=0$ is actually $360^{\circ}$ (equivalent to $0^{\circ}$ ) or $180^{\circ}$ (i.e. $0^{\circ}$ with a reversal of the direction, due to the symmetry).

At last, when the spacing of the two spots is sufficient their finite size can be neglected. The phase lag is then, as for point-like spots, equal to the ratio $x / \mu$, where $x$ is the spacing between the heating and probe spots, and $\mu$ is the "thermal diffusion length"

$$
\mu=[D / \pi f]^{1 / 2} \text {. }
$$

Consequently the wings of the plot are straight lines, whose slope yields the thermal diffusion length $\mu$. Since the modulation frequency $f$ is known, the slope finally yields the thermal diffusivity $D$. We obtain

$$
D \approx(0.81-0.87) \times 10^{-2} \mathrm{~cm}^{2} / \mathrm{s},
$$

in remarkable agreement with values found in the literature : $(0.8-0.9) \times 10^{-2} \mathrm{~cm}^{2} / \mathrm{s}$. 


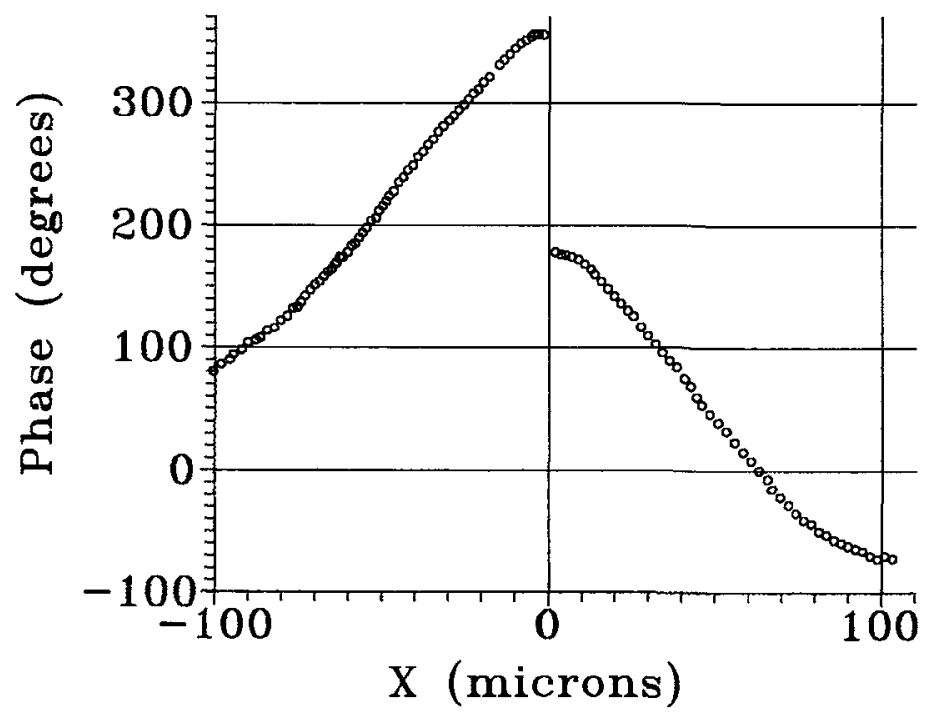

Figure 2 : Phase lag of the deviation of the probe beam with respect to the modulation of the heating beam, as a function of the position of the heating spot. (Modulation frequency : $919 \mathrm{~Hz}$; origin $x=0$ at the centre of the probe spot).

We hope this technique will be helpful in the characterisation of the local thermal properties of homogeneous or heterogeneous transparent thin films.

\section{References}

[1] Boccara A.C., Fournier D. and Badoz J., Appl. Phys. Lett. 36 (1980) 130-132.

[2] Kuo P.K., Lin M.J., Reyes C.B., Favro L.D., Kim D.S., Zhang S.Y., Inglehart L.J., Fournier D., Boccara A.C. and Yacoubi N., Can. J. Phys. 64 (1986) 1165-1167.

[3] Boccara A.C. and Fournier D., in "Photoacoustic and thermal wave phenomena in semiconductors", Mandelis A. edr. (North-Holland, New-York, Amsterdam, London,1987) pp. 237-255 and pp. 287-310.

[4] Plichon V. and Petit M.A., "Mirage detection for electrochromic materials characterisation. Application to iridium oxide films", 8th International Topical Meeting on Photoacoustic and Photothermal Phenomena, Pointe-à-Pitre 22-25 January 1994 (Les Éditions de Physique, 1994) to be published. 